\title{
Improving Eco - Efficiency Through Overcoming Sustainability Challenges: A Case Study For BSEC Member States
}

\author{
DOI: 10.7595/management.fon.2018.0016
}

Abstract:

Research question: The paper investigated whether a possibility for improving eco - efficiency of the BSEC member states exists. Motivation: The BSEC member states are primarily oriented towards accomplishing various economic goals, and they are very successful in this area. On the other hand, sustainability issue is still one of major problems for these states, since all BSEC member states do not pay full attention to sustainable development. Also, there are no quality researches that provide a deeper analysis of sustainability issues for BSEC member states and so the goal research was to explore if there exists any links between factors that have an impact on eco - efficiency of BSEC member states in order to provide sustainable solutions for the BSEC member states. Idea: The core idea of this paper was to empirically evaluate the relationship between some factors that have an impact on eco - efficiency on the BSEC member states, but also to test the implementation of the Ehrlich and Holdren equation on the BSEC member states. Data: The analysis was conducted for all 12 BSEC member states using data from several databases such as: IEA, Trading Economics and World Bank. Time series for the analyzed data starts in 1995 and ends in 2015. Tools: The statistical analysis of all collected data (descriptive statistics, correlation analysis, linear regression analysis and panel data analysis) was used to draw conclusions between the analyzed variables and check if they have statistical evaluation. Findings: The results showed that full implementation of the Ehrlich and Holdren equation among the BSEC member states is not possible due to the social aspect of the equation. The analysis also suggests that gasoline prices, $\mathrm{CO}_{2}$ emissions and renewable resources should become a vital part of the future sustainable strategies for the BSEC member states, since all these variables have a strong impact on eco - efficiency of the BSEC member states. Contribution: The paper expands the existing research literature by providing a detailed sustainable development analysis of the BSEC region, since there were no so many sustainability analyses of the BSEC region such as this in the past.

Keywords: Eco - efficiency, natural resources, sustainability, BSEC, energy use, renewable resources, panel data analysis JEL Classification: Q34, Q51, Q56.

\section{Introduction}

In the past, people used natural resources very intensively in order to achieve some economic goals and they never thought about the consequences of their activities. With a more dynamic economic and population growth a higher pressure was put on the natural resources since they became an important input for many national economies. An intensive use of natural resources leads to environmental disasters, which incited many people to start thinking more about their acts in order to avoid new disasters in the future. By accepting a sustainable development concept, many states have obliged to give more efforts in creating the world a better place for everyone, especially to improve the environmental aspect of life. Although sustainable development is on the path to become a eading doctrine of modern time, many states are facing some difficulties on their way to achieve sustainable goals.

One of the biggest challenges for all states in the sustainability area is the existence of the gap between the decreased use of resources that someone should expect from an increased eco - efficiency and their real use in the gross rebound effect (GRB) (Vehmas et al., 2004; Bauer and Papp, 2009). The rebound effect is 
actually a ratio of the lost benefit compared to the expected environmental benefit when the consumption rate of the natural resource is at a constant level. For instance, if $7 \%$ improvement in vehicle improvement fuel efficiency results in only a $2 \%$ drop in fuel, there is $71 \%$ rebound effect $((7-2) / 7=71 \%)$ which means that the missing $5 \%$ are lost in driving faster or further than before.

The GRB is closely related to the Khazzom - Brookes postulate, which suggest that energy efficiency improvements at the micro level should lead to the increased economic growth and higher energy use at the macro level (Herring, 1998). Based on theoretical approach, gross rebound effect is a much broader variable than the rebound effect since it includes the overall use of the natural resources on the national level which can sometimes offer a realistic view to the energy use in a certain country. In order to avoid the rebound effect, there are suggestions that any cost savings from the efficiency gains must go through taxation which will keep the cost of use at a constant level (Wackernagel and Rees, 1997). The market - based instruments should create financial incentives for changing the behaviour of the economic subjects for the purpose of increasing the efficiency of environmental and natural resources management (Radukic, 2012). Treating the rebound effect in early stages or on a preventive basis is important for avoiding many possible problems that can appear with the rebound effect.

The structure of the paper, besides the introduction and conclusion, includes five more chapters. The first chapter brings a brief literature review of eco - efficiency, rebound effect and the intensive use of natural resources. In the second chapter, theoretical aspect of problem in this research will be presented. The third chapter brings the analysis of economic and environmental aspects of the BSEC organization. In the fourth chapter, the Ehrlich and Holdren equation will be statistically tested on the example of the BSEC member states with a brief view to countries EPI performances. Since eco - efficiency is one of the elements of the Ehrlich and Holdren equation, in chapter five the factors that have an impact on eco - efficiency will be analysed in order to give an overall view of the rebound effect problem in the BSEC member states.

\section{Literature Review}

Wackernagel and Reese (1997) argue that perceptual distortions and prevailing economic rationality, far from encouraging investment in natural capital, actually accelerate the full use of natural capital stocks. The authors analyze the ecological footprint as a biophysics measure of such capital, and apply this concept as an analytical tool for examining the barriers to investing in natural capital. The authors show why low prices cannot affect ecological necessities, how interregional risk pooling encourages resource liquidation, how some terms of trade undermine both local and global ecological stability and how efficiency strategies may actually accelerate resource throughput. Sorrell and Dimitropoulous (2008) have analyzed all limitations and extensions of the rebound effect. The authors have examined the rebound effect through efficiency and price elasticity and they have discovered three types of effects that could occur with the appearance of the rebound effect. The first one is a direct rebound effect, which can be seen as an intensive use of goods through their lower costs of use. The second one is the indirect rebound effect. The third one is economy wide effect. The fall in service costs reduces the price of other goods and creates new production possibilities with the parallel increase of economy growth. Gijum et al. (2008) have analyzed how the use of natural resources in Europe is sustainable. The authors presented the three possible scenarios for possible treatment of natural resources on the European and global levels. In the baseline scenario, thr used domestic extraction within the EU remains roughly constant until 2020, while unused domestic extraction decreases (particularly overburden from mining activities). The results suggest that policy instruments for raising the eco-efficiency on the micro level so they can impact the economic growth.

Holm and Englund (2008) analyzed the correlation between eco - efficiency and the gross rebound effect. Their analysis involved the USA and six European countries. The authors have found that during 1960-2002 the difference between a potential decrease of natural resources use and their real use was growing faster in the USA than in the six analyzed European countries. The authors also showed that the environmental existence of Kuznets curve could not be supported since all analyzed groups have started to make a long distance from improving the ecological footprint. Wang et al. (2016) have provided an empirical analysis of the rebound effect through a case study on electrical consumption of Beijing inhabitants. The size of the rebound effect largely determines the effectiveness of energy efficiency in mitigating energy consumption. The three income-elasticity, weight change, and proportional re-spending scenario simulation results show that: the residential electricity use in Beijing exhibits a partial rebound effect; the long-term direct and indirect rebound effects are $46 \%$ to $56 \%$; the short-term direct rebound effect is $24 \%$ to $37 \%$. Chen et al. (2017) tried to test the process of sustainable development in Macau. Their research adopted embodied (direct plus indirect) greenhouse gas (GHG) emissions to acquire the decoupling indicators in Macao from 2000 to 2013. As for total em- 
bodied GHG emissions (TEGE), the results showed that Macao's economy has experienced several decoupling stages, with a distinct tendency towards strong decoupling. When comparing decoupling indicators of TEGE in terms of systematic accounting with that of direct accounting, many differences are visible. As for total energy consumption (TEC), Macao's TEC has decoupled from its economic growth.

\section{The Implementation of the Ehrlich and Holdren Equation in Explaining the Rebound Effect}

The rebound effect is that kind of a problem that looks for a better treatment in order to prevent future environmental problems. Although the rebound effect can produce some effects on the use of natural resources, it can also have an impact on the net effect of societies overall resources use due to consumption patterns, population development and the degree of eco - efficiency (Jokinen et al., 1998). The rebound effect can also lead to an inefficient use of natural resources and a higher energy intensity for most of the states. A high level of energy intensity can become a huge problem, since it can lead to the exhaustion of the non-renewable resources, which will leave states without important resources. Therefore, transition to renewable resources is required. Some analyses have shown that states such as the Republic of Serbia and Bosnia \& Herzegovina have a very high energy intensity which is not good for solving the rebound effect, but if these states decide to increase the use of renewable resources for $1 \%$, they will improve the energy intensity for 0.452 percentage points (Perovic and Radukic, 2017).

For a too long time, many environmentalists have tried to discover a right formula that will include all important factors that have an impact on the environment. In particular, some have drawn attention to potential inter-relationships among the three factors and others have wished to stress other factors that were not included in the formula, such as political and social structures, scopes for beneficial activities or harmful environmental actions. Ehrlich and Holdren (1971) were among the first ones who tried to describe the real impact that many factors have on the environment, but in a simpler manner. The authors were the first to describe the impact of human activities on the environment through the following formula:

$I=$ PAT(1)In this formula (I) stands for the environmental impact, (P) for the population size, $(A)$ for the affluence and $(T)$ for the effects of technology. The largest possible sustainable impact is the carrying capacity and as long as (I) is less than this amount the associated population, affluence and technology that are responsible for (I) are sustainable. Since the carrying capacity represents the number of people which a region can support without committing environmental degradation, it is important that value (I) does not exceed the overall value of other variables in the equation or in that case economic degradation will appear and sustainable solutions will not be sufficient in solving environmental problems. Variable $(P)$ represents the total population size of an examined area and this value is a frequent subject of changes due to differences in fertility, mortality and migration rates that exist in many states. Variable $(A)$ is an expression of the affluence, which represents the average consumption of every person in the world or, in particular, in the analyzed models. The common proxy for the $(\mathrm{A})$ variable is the GDP per capita since it includes both economic and demographic factors in providing the right answers connected to production changes. People spend their income on many products and goods which in the end become waste and another worry for the authorities that take care of the environment. Variable $(T)$ shows what an intensive use of resources during the production process really is like. This variable examines the environmental impact on creating, transporting and disposing of the goods and services during their permanent use. With the improvements in resources the use value of variable $(T)$ will fall down, which means reduced and effective use of the resources. For some authors, variable $(T)$ represents the eco - efficiency since it reveals how efficient the use of the resources really is (Holm and Englund, 2008).

The Ehrlich and Holdren equation has also become a subject of criticism that has involved many aspects of the equation. Some authors have pointed out that the equation is very simplified and that in the reality at least 7 independent relations between variables $(P),(A)$ and $(T)$ exist, which only indicates that it is better to rewrite the equation as a I $=f(P, A, T)$ (Alcott, 2010). Another critic of the equation pledges not including the life style of various social groups whose behaviour is sometimes harmful to the environment and that is why behaviour variable (B) should be included in the equation (Schulze, 2002). The equation model depicts people as being purely harmful to the environment, ignoring any conservation or restoration efforts that societies have made and it also does not take into account varying degrees of power, influence and responsibility of humans over the environmental impact (Moseley, 2014). This actually means that $(P)$ variable does not include complex social behaviours, which in the end puts pressure on poor households to bear the cost of environmental externalities. The Ehrlich and Holdren equation is also being criticized for not accounting for the sustainable resource use among some low-income and indigenous groups, characterizing these groups as cultures that support low impact practices (Moseley, 2014). 
With all known criticism of the Ehrlich and Holdren equation, it can have a practical evaluation on many occasions. Carbon and water footprint analysis considers the Ehrlich and Holdren equation where factors affect $\mathrm{CO}_{2}$ and water resources and change the strength of their relation. The equation is helpful in assessing the impact of different PAT factors to greenhouse gas (GHG) emissions. Some reports have shown that the levels of GHG emissions for affluent states increase with higher amounts of affluence, while both population and the level of affluence are significant factors in GHG emission trends in states with a higher poverty rate (Cole \& Neumayer, 2004). In addition to highlighting the population impact on the environmental problems, the IPAT made two other significant contributions. It drew attention to the fact that environmental problems are more than pollution, and that they involve multiple factors that by joining together can produce a compounding effect. Subsequent research using the IPAT indicates that some researchers assume that simple multiplicative relationship among the main factors generally does not hold - doubling population, such as, does not necessarily lead to a doubling of impact (Chertow, 2001). The IPAT equation helped in understanding the multiple causes of environmental impact, as it continues to use developing techniques such as methods for improving our understandings of these issues.

\section{Economic and Environmental Analysis of the BSEC}

BSEC (The Organization of the Black Sea Economic Cooperation) represents a regional international organization focusing on the multilateral political and economic initiatives for close cooperation, peace, stability and prosperity of the countries in the Black Sea region. In 1992, 11 states signed the Summit Declaration and the "Bosphorus Statement" in Istanbul and founded the BSEC. Two years later, the BSEC started to work more actively and in 1999 the BSEC became a full regional economic organization. The member states of the BSEC are: Albania, Armenia, Azerbaijan, Bulgaria, Georgia, Greece, Moldova, Romania, Russia, Serbia, Turkey and Ukraine. Among these members only Serbia did not access the BSEC in the beginning due to sanctions imposed by the UN. Serbia became a member of the BSEC in 2004 and started to bring out all contracts and documents in the BSEC. One of the most important activities of the BSEC is finding the right solutions to improving the development of SME and entrepreneurship in all member states through organizing frequent meetings on enhancing the regional economic cooperation. In order to give full support to the economic cooperation the BSEC formed the Black Sea Trade and Development Bank (BSTDB) in Thessaloniki, Greece. The main role of the BSTDB is to support all development projects of all public and private companies in all member states and to promote regional trade, cross-country projects and foreign direct investments.

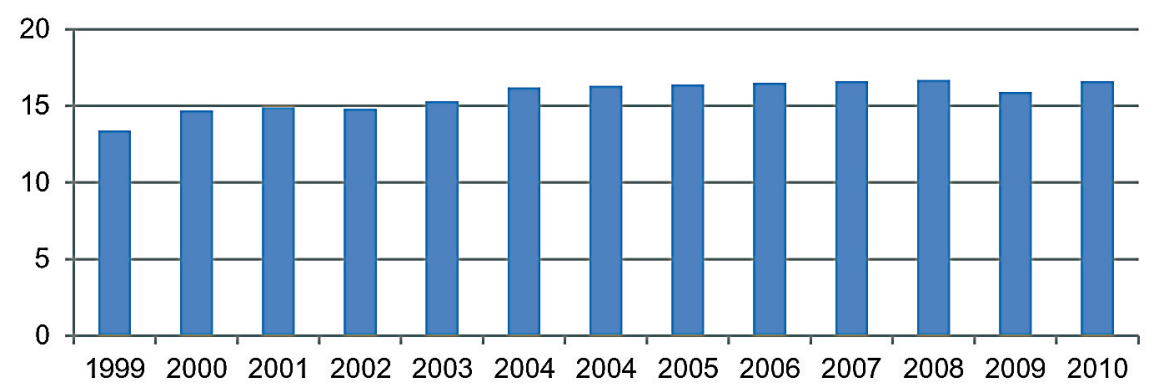

Figure 1: Intra - regional trade in the BSEC region in $1999-2010$ (\%)

Source: Konrad-Adenauer-Stiftung (2017). The Organization of Black Sea Economic Cooperation

(BSEC) - A mechanism for integration in a geopolitical area. Retrieved from $\mathrm{h}$

The intra-regional trade is very important for the BSEC since it is one of the main indicators that can show real economic values of the BSEC organization. Based on Figure 1, the intra-regional trade increased slowly during the eleven year period, which is a good sign. This means that the BSEC member states have a very good perspective to work on the further improvement of the intra-regional trade. One of the future plans of the BSEC includes improving road and railway infrastructure between the member states, so intra-regional trade can continue to increase. Since all the BSEC members are developing countries, they have a strong intention to cooperate in overcoming all difficulties that all economies of the BSEC have. The BSEC, with an economic volume of about $€ 4$ trillion and a population of 330 million people is still a very young but promising market, especially for those members that want to improve foreign trade balances. 

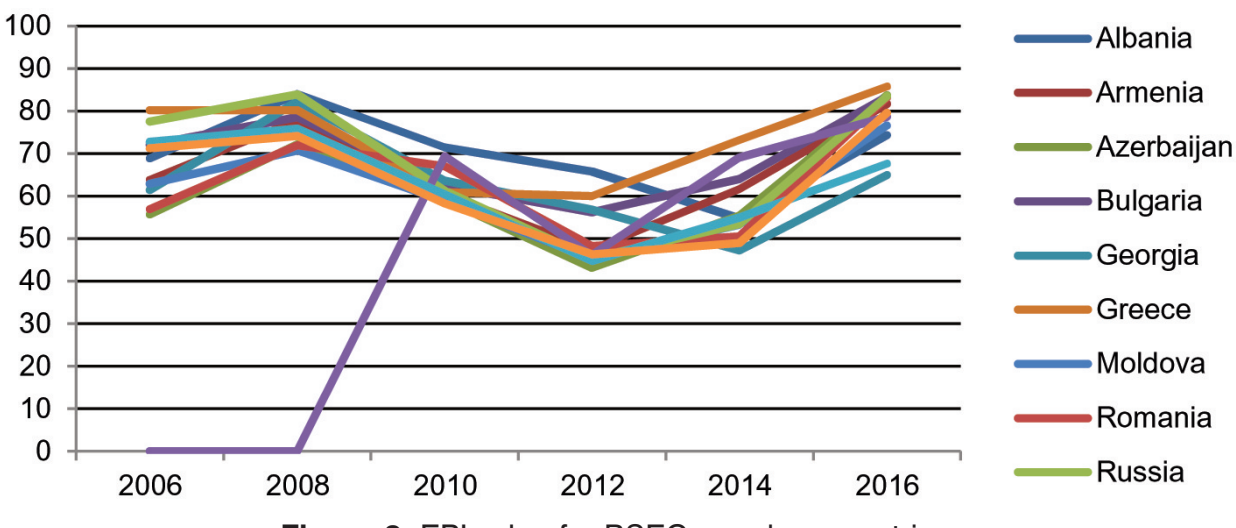

Figure 2: EPI value for BSEC member countries

Source: Environmental Performance Index (2017). Yale University. Retrieved from

In addition to economic cooperation which certainly is important for the BSEC member states, environmental issue is another important area for all member states. The EPI values showed that there is a huge difference in the way the BSEC member states treat environmental issues. For instance, Albania had good EPI values until 2014 when it suffered a huge fall. It is the same with Georgia, which has the lowest EPI value among the BSEC members, while, on the other hand, Greece and Azerbaijan report the highest EPI values (Figure 2). Many of these states have enough space to make progress in the environmental area, but that progress is still not visible since the economic goals are a top priority for all the BSEC member states. These states carry out a large nmber of international agreements and economic instruments in the environmental area, but they need to make more efforts if they all want to improve their current environmental performances. Coordinating between economic and environmental goals is something that all the BSEC member states will be facing in the near future and improving environmental performances will depend on efforts that the BSEC member states are willing to make in order to solve the environmental problems.

\section{Testing the Ehrlich and Holdren Equation on the BSEC Member States}

As said above, one of the ways for measuring the environmental impact is through the Ehrlich and Holdren equation. Testing the Ehrlich and Holdren equation on the group of the BSEC member states involves the 1995 - 2015 time period. The availability of data was crucial in selecting the period, but also because in that period Serbia applied for membership in this regional organization. Since the idea of the statistical analysis is to show if it possible to test the Ehrlich and Holdren equation on the BSEC member states, the research must include a proper choice of the variables.

For the purpose of the analysis the panel data model is used and it will be presented through fixed effects model. The analysis involves the period of 1995-2015, while data were used from databases such as: IEA, United Nations and World Bank. Usually used as a dependent variable (I) in the equation is the ecological footprint. Since the ecological footprint has some limitations (mainly in data), energy use was chosen as a substitute variable because it has a very high correlation with the ecological footprint (Hails et al., 2006). (T) is another independent variable, since our interest is to see if there is any kind of impact on the energy use. Since $(T)$ also represents the eco-efficiency variable, it is interesting to analyze if this variable has any impact on the environment of the BSEC member states. In this analysis electricity consumption per capita represents the $(T)$ variable. Variable $(P)$ is described through population growth rate, while variable $(A)$ is defined through GDP per capita (PPP). The choice of values for the analyzed variables was made in order to avoid huge differences in population number and the strength of the economies that exist among the BSEC member states. Although all elements of Ehrlich and Holdren equation are important for the research, we must have in mind the research goal which is related to the environmental issues and so eco-efficiency will have a slight advantage over the other two elements of the equation. As the final variable, the financial crisis was chosen. Therefore, a dummy variable stands for the financial crisis since in 2008 and 2009 the BSEC member states suffered substantial setbacks in their economies. For the purpose of research, several datasets and publications served for taking out proper data (International Environmental Agency, 2017; United Nations, 2017; World Bank Group, 2017). After explaining basic statistical rules and describing data, the starting hypothesis will be:

H1: Eco-efficiency has a positive significant impact on the environment of the BSEC member states. 
As it was earlier mentioned, the fixed effects model is primary a statistical choice for the analysis for 12 BSEC member states and so we have the following number of countries $I=1, . .12$. Since the analysis involves the period of $1995-2015$, the time variable is $t=21$, so the adequate equation for the model is:

$$
y_{i t}=\alpha+x_{i t} \beta+c_{i}
$$

where $\mathrm{y}_{\mathrm{it}}$ stands for the dependent variable, $\alpha$ for the constant, $\mathrm{x}_{\mathrm{it}} \mathrm{K}$ for the dimension row of vector that represents independent and dependent variable, $\beta$ for $\mathrm{K}$ dimension column of vector value for dependant and independent variables, $c_{i}$ is the specific impact of the analyzed economy, and $u_{i t}$ represents the residual (Baltagi, 2001; Wooldridge, 2002). Prior to selecting the model, all adequate tests should follow the analysis meant for the choice of a proper model. All data and models in this analysis passed various statistic tests in Stata 12 software.

Table 1: Descriptive statistics

\begin{tabular}{|cccccc|}
\hline Variable & Obs & Mean & Std. Dev. & Min & Max \\
\hline Ecofoot & 252 & 0.009484 & 2.197881 & .01 & 10.5 \\
Popgrowth & 252 & -.3244048 & 1.153133 & -2.43 & 2.25 \\
Gdpgrowth & 252 & 1.698611 & 1.593787 & -4.39 & 5.37 \\
Ecoefficiency & 252 & 0.980952 & 1.464112 & .66 & 6.62 \\
Fincriis & 252 & .0923077 & .2900181 & 0 & 1 \\
\hline
\end{tabular}

Source: Authors' calculation

Prior to testing the Ehrlich and Holdren equation, the analysis will start with the descriptive statistics and correlation analysis in order to prepare data for a panel data model. Table 1 first shows the minimum and maximum values where the highest range is exhibited by two dependent variables, GDP growth (PPP) (A) and population growth $(P)$. The highest range is due to constant changes in GDP (PPP) growth, but also due to population growth since some states have higher mortality rate than others. As regards the dependent variable, i.e., energy use (I), and since its value of standard deviation is higher than its mean value, all conditions are in favour of further analysis that includes correlation analysis and testing the model. Further analysis should provide the answers to the strength of relation between IPAT components and their interpersonal impact.

Table 2: Correlation analysis of IPAT components

\begin{tabular}{|lccccc|}
\hline & Ecofoot & Popgrowth & Gdpgrowth & Ecoefficiency & Fincrisis \\
\hline Ecofoot & 1.000 & & & & \\
Popgrowth & 0.0758 & 1.000 & & & \\
& 0.2308 & & & & \\
Gdpgrowth & -0.1001 & 0.0355 & 1.000 & & \\
& 0.1128 & 0.5752 & & & \\
Ecoefficiency & $0.6141^{*}$ & 0.0329 & $-0.1517^{*}$ & 1.000 & \\
Fincrisis & 0.0000 & 0.6028 & 0.0159 & & \\
& $0.1434^{*}$ & -0.0015 & $-0.0385^{*}$ & 0.1497 & \\
\hline
\end{tabular}

Source: Authors' calculation

The correlation analysis shows that among all independent variables, only eco-efficiency $(T)$ and dummy variable have a statistically significant relation with the energy use. This significance in case of eco-efficiency is $(0.000)$, while for dummy variable it is $(0.043)$. There is a strong relation between eco-efficiency and energy use (0.614), while the coefficient of correlation between the dummy variable and energy use is $(0.143)$. On the other hand, population growth and GDP growth (PPP) are not correlated to other variables. After the correlation analysis, the model will be assessed through the panel data model. 
Table 3: Panel data analysis

\begin{tabular}{|c|c|c|c|c|c|c|}
\hline & & & & & Number & bs $=252$ \\
\hline & & & & & Number of & oups $=12$ \\
\hline R-Sq: withi & $=0.4204$ & & & & Obs per gr & $\min =21$ \\
\hline betwee & $=0.3724$ & & & & & $\operatorname{avg}=21.0$ \\
\hline overa & $=0.2964$ & & & & & $\max =21$ \\
\hline & & & & & $F(4,23$ & $=4.47$ \\
\hline Corr(u_i, Xk & $=0.4303$ & & & & Prob > & $=0.0017$ \\
\hline Ecofoot & Coef. & Std. Err. & $t$ & $P>|t|$ & {$[95 \%$ Co } & Interval] \\
\hline Ecoefficiency & 0.5441426 & 0.0856921 & 3.89 & 0.000 & -.0246766 & .8959617 \\
\hline Popgrowth & 0.0337794 & 0.0514235 & 0.66 & 0.512 & -.0675283 & .1350871 \\
\hline Gdpgrowth & 0.0545838 & 0.0270699 & 2.02 & 0.045 & .0012542 & .3079133 \\
\hline Fincrisis & 0.4875954 & 0.1381307 & 3.53 & 0.000 & .2154687 & .7597222 \\
\hline _cons & 0.4573717 & 0.1907636 & 2.31 & 0.035 & -.05635 & .9710934 \\
\hline sigma_u & 29007432 & & & & & \\
\hline sigma_e & .57937872 & & & & & \\
\hline rho & .20564882 & & & & & \\
\hline
\end{tabular}

Source: Authors' calculation

Table 3 shows the way in which some components of the Ehrlich and Holdren equation have impact on ecological footprint (energy use). Among the independent variables, eco-efficiency (T) and GDP growth have an impact on energy use (I) if statistical significance is observed. If electric consumption per capita increases by only $1 \%$, there will be an increase in energy use by 0.544 percentage points. Therefore it is recommended that the null hypothesis should be rejected since eco-efficiency really has a statistically significant impact on the energy use. In case of GDP growth, if it increases by $1 \%$, then the estimated energy use will increase by 0.054 percentage points. On the other hand, the presented model shows that a full statistical significance of the Ehrlich and Holdren equation does not exist, since population growth does not have a statistically significant impact on the energy use. This actually means that the BSEC member states do not fully satisfy the conditions of the Ehrlich and Holdren equation and because of that a full capacity of the Ehrlich and Holdren equation cannot be reached in case of the BSEC member states.

\section{Identifying the Driving Factors of the Eco-efficiency for BSEC Member States}

After discovering that technology has an impact on the environment of the BSEC member states, further analysis will include factors that have an impact on eco-efficiency. World Business Council for Sustainable Development describes eco-efficiency as "conditions achieved by the delivery of competitive-price goods and services that satisfy human needs and bring quality to life, while progressively reducing ecological impacts and resource intensity throughout the life cycle to a level at least in line with Earth's estimated carrying capacity" (WBCSD, 2001, p.7). After every new environmental accident, the eco-efficiency concept is always presented as one of the best solutions to avoid future environmental risks. The eco-efficiency concept covers many areas, from preventive actions, manufacturing, product placement, resource use and human resource which all tells that eco-efficiency is actually a multidisciplinary conceptual framework, where environment is in the first place.

The BSEC member states are also among the states that have accepted the eco-efficiency framework in order to improve environmental performances, but the results of their activities vary from country to country. Differences in environmental performances exist because not all of the BSEC member states have the same mechanisms for improving the environmental protection systems and they also differ in a way they pursue their environmental policies (Aall and Husabo, 2010). For some countries water and land qualities are primary issues, for others it is air quality and this all has an impact on making a decision about the use of an adequate eco-efficiency concept. On the other hand, the eco-efficiency concept is very dependable on the natural resources and the way how policymakers see eco-efficiency as a tool for improving environmental performances (Basuki, 2015). To give a good analysis of the eco-efficiency concept, some driving factors must come to the top position during the process of identification. In order to analyze the impact on the eco-efficiency of the BSEC member states, certain variables must pass several tests first. For the purpose of this research 
the following variables are taken as appropriate: gasoline prices, $\mathrm{CO}_{2}$ emissions per capita, coal production growth rate and the use of renewable resources for electricity production. The selection of these factors is mainly caused and made by the intensive use of fossil fuels that are partially responsible for environmental problems, since coal and gasoline are important parts of economies and traffic, while $\mathrm{CO}_{2}$ emissions are the result of the intensive fossil fuel use. As regards the renewable resources, their use represents one of the best ways to solve environmental problems, since they do not harm the environment.

In the following analysis the standard linear regression model is in the focus of the implementation but this time with different variables. This time eco-efficiency (electricity consumption per capita) is selected as a dependent variable, while petrol prices, $\mathrm{CO}_{2}$ emissions per capita, coal production growth rate and the use of renewable resources for the production of electricity are selected as independent variables. The dummy variable was also included in the analysis as an independent variable to see if global financial crisis affected the eco-efficiency of the BSEC member states. For the purpose of this research several datasets served for taking out proper data: IEA, United Nations and the World Bank. Therefore, we come to following hypothesis:

H2: Petrol prices have a positive, while $\mathrm{CO}_{2}$ emissions per capita have a negative and statistically significant impact on eco-efficiency.

H3: The use of renewable resources has a positive and statistically significant impact on eco-efficiency.

Table 4: Descriptive statistics

\begin{tabular}{|cccccc|}
\hline Variable & Obs & Mean & Std. Dev. & Min & Max \\
\hline Ecoefficiency & 252 & .980952 & 1.464112 & .66 & 6.62 \\
Petrolprice & 252 & .9646032 & .3451904 & .39 & 2.17 \\
CO2emiss & 252 & 4.746151 & 3.143738 & .48 & 12.78 \\
Coalprod & 252 & .54404706 & 4.383855 & -14.91 & 17.29 \\
Renewables & 252 & .6060317 & 1.746472 & -3.78 & 5.64 \\
Fincrisis & 252 & .0923077 & .2900181 & 0 & 1 \\
\hline
\end{tabular}

Source: Authors' calculation

Based on the descriptive statistics in table 4, we can see that the standard deviation value for the dependent variable (1.46143) is higher than the mean value (0.9809). As regards the other variables, all of them, with the exception of renewable resources, exhibit a higher mean value than the standard deviation value. It can be seen from table 4 that coal production has very high values, since it is important for the production of electricity (Covert et al., 2016). Among the analyzed variables coal production has the highest range value, since the minimum value is 14.91 , while the maximum value is 17.29 . The $\mathrm{CO}_{2}$ emissions also have very high range values, where the minimum value is 0.48 and the maximum value is 12.78 . This indicates that the air pollution problem is not treated appropriately among the BSEC member states and that all member states should make better efforts in solving the problem of high $\mathrm{CO}_{2}$ emissions.

After descriptive statistics, the correlation analysis will be implemented in order to discover possible relations between the variables. The correlation analysis will help in estimating the strength and direction of correlation between all analyzed variables.

Table 5: Correlation analysis of eco-efficiency and independent variables

\begin{tabular}{|lcccccc|}
\hline & Ecoefficiency & Petrolprices & CO2emiss & Coalprod & Renewables & Fincrisis \\
\hline Ecoefficiency & 1.000 & & & & & \\
Petrolprices & $0.1570^{\star}$ & 1.000 & & & & \\
& 0.0126 & & & & & \\
CO2emiss & $-0.9052^{\star}$ & -0.0380 & 1.000 & & & \\
& 0.000 & 0.5478 & & & & \\
Coalprod & 0.1001 & -0.0847 & $0.1248^{\star}$ & 1.000 & & \\
& 0.1131 & 0.1802 & 0.0478 & & & \\
Renewables & $0.2617^{\star}$ & 0.0247 & -0.0041 & -0.1055 & 1.000 & \\
& 0.0195 & 0.6967 & 0.9489 & 0.0947 & & \\
Fincrisis & 0.0497 & $0.1542^{\star}$ & 0.0014 & -0.0424 & 0.0132 & 1.000 \\
& 0.4326 & 0.0143 & 0.9820 & 0.5033 & 0.8345 & \\
\hline
\end{tabular}

Source: Authors' calculation 
The correlation analysis shows that eco-efficiency has a statistically significant relation with petrol prices (0.012), $\mathrm{CO}_{2}$ emissions per capita $(0.000)$ and renewable energy consumption growth rate $(0.019)$. Among these variables eco-efficiency has the strongest correlation with $\mathrm{CO}_{2}$ emissions per capita (-0.905), while the strength of relation with renewable energy consumption growth rate is 0.261 and, together with petrol prices, it amounts to 0.157 . Coal production and dummy variable do not show any signs of statistically significant relation with eco-efficiency. After discovering the strength and direction of correlation between analyzed variables, further analysis will be continued with the implementation of the regression analysis.

Table 6: Eco-efficiency regression analysis

\begin{tabular}{|c|c|c|c|c|c|c|}
\hline Source & ss & df & MS & & \multicolumn{2}{|c|}{ Number of obs $=252$} \\
\hline Model & 463.331975 & 5 & 92.6663951 & & \multicolumn{2}{|c|}{$F(5,246)=305.09$} \\
\hline Residual & 74.7179962 & 246 & .303731692 & & \multicolumn{2}{|c|}{ Prob $>F=0.0000$} \\
\hline Total & 538.049971 & 251 & 2.14362538 & & \multirow{3}{*}{\multicolumn{2}{|c|}{$\begin{array}{l}\text { R-squared }=0.8611 \\
\text { Adj R-squared }=0.8583 \\
\text { Root MSE }=.55112\end{array}$}} \\
\hline & & & & & & \\
\hline & & & & & & \\
\hline Ecoefficiency & Coef. & Std. Err. & $\mathbf{t}$ & $P>|t|$ & \multicolumn{2}{|c|}{ (95\% Conf. Interval) } \\
\hline Petrolprices & .1977929 & .0123703 & 5.79 & 0.000 & .0961589 & .7894269 \\
\hline CO2emiss & -.2841293 & 2034869 & -2.34 & 0.037 & -.5887257 & .1624672 \\
\hline Coalprod & .0031536 & .0080713 & 0.39 & 0.696 & -.0127441 & .2190514 \\
\hline Renewables & .3175433 & .0200337 & 2.57 & 0.011 & .0120838 & .6910027 \\
\hline Fincrisis & .0942407 & .1197638 & 0.79 & 0.432 & -.1416526 & .330134 \\
\hline cons & .1138056 & .1182351 & 2.86 & 0.002 & -.1190766 & .3466878 \\
\hline
\end{tabular}

Source: Authors' calculation

The regression analysis shows that petrol prices, $\mathrm{CO}_{2}$ emission per capita and renewable energy consumption have a statistically significant impact on eco-efficiency. The analysis shows one interesting thing, though - if petrol prices rise by $1 \%$, the estimated eco-efficiency will increase eco-efficiency 0.197 percentage points. This means that companies and individuals will look for alternative fuels that are less expensive and that do not pollute the environment. The ynalysis also shows that a reduction in $\mathrm{CO}_{2}$ emission per capita by only $1 \%$ will increase the estimated eco-efficiency by 0.284 percentage points. Intensive renewable energy consumption will also affect the eco-efficiency since the single increase in renewable energy consumption will increase the estimated eco-efficiency by 0.317 percentage points.

The statistical analysis shows that the eco-efficiency of the BSEC member states can be improved if these states decide to use renewable resources more intensively. The analysis shows that environmental processes will be crucial for the future economic development of the BSEC member states because the future growth of the electricity prices will "certainly encourage individuals and legal entities to use energy from the renewable resources, e.g., heating, using solar energy or energy derived from the biomass" (Zdravkovic et al., 2012, p. 390). Economic and environmental priorities differ in most of the BSEC member states, where under some circumstances economic issues have an advantage over the environmental issues. Therefore, it is important for all BSEC member states to start the optimization of models that include both economic and environmental issues. Based on the optimization model, "every country can define the most desirable economic and environmental policy, and respond appropriately in order to increase the level of economic growth and quality of the environment, meaning social well-being" (Radukic et al., 2012, p. 690). 


\section{Conclusion and Recommendations}

A low level of eco-efficiency is usually the main cause of many environmental problems and it is also one of the crucial factors for the increase and broader visibility of the rebound effect in the world. the rebound effect brings unnecessary and undesirable costs to all economic subjects in the long term, hence it is important to begin solving this problem immediately and start with effective and efficient use of the natural resources. After testing the Ehrlich and Holdren equation on the BSEC member states, the results show that affluence and technology have a statistically significant impact on the environment. On the other hand, the analysis shows that the population growth rate does not have a statistically significant impact on the environment, which means that full implementation of the Ehrlich and Holdren equation is not impossible in the case of the BSEC member states.

The analysis has confirmed the $\mathrm{H} 1, \mathrm{H} 2$ and $\mathrm{H} 3$ hypotheses and shown that eco-efficiency is an acceptable variable for achieving sustainable development goals. A higher price of petrol will more than probably turn the attention to the renewable resources, which can help in reducing $\mathrm{CO}_{2}$ emissions per capita and increasing the consumption of electricity through their intensive use. The BSEC member states have huge potentials for using the renewable resources, but still there are no visible improvements judging from their environmental performances. Since eco-efficiency is linked with the rebound effect through an intensive use of non-renewable resources, the statistical analysis has shown that an intensive use of renewable resources can improve eco-efficiency of the BSEC member states, which will in the long run slowly reduce the value of the rebound effect in the analyzed region. This is something which is desirable from the environmental aspect of sustainability. The BSEC member states should consider creating effective environmental strategies where renewable resources will be a priority since all other natural resources are very close to their limits. Another important thing is to structure appropriate laws based on the "polluter pays principle" with very strict penalty policies. It is also important that environmental issue must be in the same correlation (or even higher) with the economic issue. All future economic activities should assess environmental aspect of business if people have a strong will to avoid any possible accidents. Finally, all BSEC member states should create an environmental joint venture and coordinate their activities in order to improve the overall environmental performances.

The eco-efficiency concept will become more important in the future and so future studies should analyze certain areas of the eco-efficiency concept with the aim of achieving the best possible results. The future analysis should consider an intensive use of renewable resources through identifying areas where their use is important for reducing a large number of costs. Analysis should help in discovering some creative ideas for small and medium enterprises that will become the carriers of the eco-efficiency concept in the future. It is a final moment for policymakers to consider a larger scale implementation of the sustainable development concept in all areas and to start reconsidering current economic and social activities to create a world as a much better, healthier and safer place for all.

\section{Acknowledgements}

Parts of this paper have been presented at the conference "Sustainable growth in small open economies" on 26 $6^{\text {th }}$ October, 2017, at the Institute of Economic Sciences in Belgrade. The paper presents results of the project number III 44007 supported by The Ministry of Education, Science and Technological Development of the Republic of Serbia.

\section{REFERENCES}

[1] Aall, C., \& Husabo, I. A. (2010). Is Eco - Efficiency Sufficient Strategy for Achieving Sustainable Development? The Norwegian case. Sustainability 2, 3623-3638. DOI: 10.3390/su2123623.

[2 Alcott, B. (2010). Impact caps: Why population, affluence and technology strategies should be abandoned. Journal of Cleaner Production, 18(6), 552-560. DOI:10.1016/j.jelpro.2009.08.001.

[3] Baltagi, B. H. (2001). Econometric Analysis of Panel Data (2nd edition). New York: John Wiley \& Sons.

[4] Basuki, B. (2015). Eco - Efficiency and Sustainable Development as Efforts to Produce Environmental Friendly Product: An Exploratory Case Study. Issues in Social and Environmental Accounting, 9(3), 199218.

[5] Bauer, D., \& Papp, K. (2009). Book Review Perspectives: The Jevons Paradox and the Myth of Resource Efficiency Improvements. Sustainability: Science, Practice \& Policy, 5(1), 48-54.

[6] Chen, B., Yang, Q., Li, J.,S. \& Chen, G.,Q. (2017). Decoupling analysis on energy consumption, embodied GHG emissions and economic growth - The case study of Macao. Renewable and Sustainable Energy Reviews 67, 662-672. DOI:10.1016/j.rser.2016.09.027.

[7] Chertow, M., R. (2001). The IPAT equation and Its Variants - Changing Views of Technology and Environmental Impact. Journal of Industrial Ecology, 4(4), 13-29. 
[8] Cole, M., A, \& Neumayer, E. (2004). Examining the impact of demographic factors on air population. Population Environment, 26(1), 5-21.

[9] Covert, T., Greenstone, M. \& Knittel, C. R. (2016). Will We Ever Stop Using Fossil Fuels. Journal of Economic Perspectives, 30(1), 117-138.

[10] Ehrlich, P., R., \& Holdren, J., P. (1971). Impact of Population Growth. Science 171, 1212-1217.

[11] Environmental Performance Index (2017). Yale University.

[12] Gijum, S., Behrens, A., Hinterberger, F. \& Mayer, B. (2008). Modeling scenarios towards a sustainable use of natural resources in Europe. Environmental Science \& Policy, 11(3), 204-216. DOI:10.1016/j.envsci.2007.07.005.

[13] Hails, C., Loh, J. \& Goldfinger, S. (Eds.). (2006). Living Planet Report 2006. Gland: World WildLife Found for Nature (WWF).

[14] Herring, H. (1998). Does Energy Efficiency Save Energy? The debate and its consequences. Applied Energy, 63(3), 209-226. DOI:

[15] Holm, S., \& Englung, G. (2009). Increased eco - efficiency and gross rebound effect: Evidence from USA and six European countries 1960-2002. Ecological Economics 68, 879-887. DOI:10.1016/j.ecolecon.2008.07.006

[16] Energy Agency (2017). World Energy Outlook 2017. Retrieved from

[17] Jokinen, P., Malaska, P. \& Kavi-oja, J. (1998). The environment in an information society - A transition stage towards a more sustainable development? Futures, 30(6), 483-498.

[18] Konrad-Adenauer-Stiftung (2017). The Organization of Black Sea Economic Cooperation (BSEC) - A mechanism for integration in a geopolitically area. Retrieved from

[19] Moseley, W. (2014). An Introduction to Human-Environment Geography: Local Dynamics and Global Processes. Hoboken: Wiley-Blackwell.

[20] Perovic, D., \& Radukic, S. (2017). An impact of renewable resources on energy intensity in the Republic of Serbia. Ecologica 85, 33-38. DOI:

[21] Radukic, S. (2012). Economic aspects of the environmental policy on the Republic of Serbia in the light of its legislation. Teme, 36(2), 643-662.

[22] Radukic, S., Popovic, Ž., \& Stankovic, J. (2012). The goals and limitations of multi-criteria models of environmental protection. Economic Themes, 50(4), 679-692.

[23] Schulze, P., C. (2002). I=PAT. Ecological Economics, 40(2), 149-150.

[24] Sorrell, S., \& Dimitropoulos, J. (2008). The rebound effect: Microeconomic definitions, limitations and extensions. Ecological Economics, 65(3), 636-649. DOI: 10.1016/j.ecolecon.2007.08.013.

[25] Vehmas, J., Luukanen, J., \& Kavio-oja, J. (2004, May). Technology development versus economic growth-An analysis of sustainable development. In: EU-US seminar: New Technology Foresight, Forecasting \& Assessment Methods (pp. 13-14).

[26] Wackernagel, M, \& Rees, W. (1997). Perceptual and structural barriers to investing in natural capital: Economics from an ecological footprint perspective. Ecological Economics, 20(1), 3-24.

[27] Wang, Z., Hai, B. \& Lu, M. (2016). Measurement of energy rebound effects in households: Evidence from residential electricity consumption in Bejing, China. Renewable and Sustainable Energy Reviews 58, 852-861. DOI:10.1016/j.rser.2016.09.027.

[28] WBCSD - World Business Council for Sustainable Development (2001). Measuring eco - efficiency - A Guide to Reporting Company Performance. Geneva: World Business Council for Sustainable Development (WBCSD).

[29] Zdravkovic, D., Radukic, S., \& Veselinovic, M. (2012). Perspectives of renewable energy utilization in the Republic of Serbia. Facta universitatis: Economics and Organization, 9(3), 381-391.

[30] United Nations (2017). World Population Prospects 2017. Retrieved from https://esa.un.org/undp/wpp/Publications

[31] Wooldridge, J. M. (2002). Econometric Analysis of Cross Section and Panel Data. Cambridge, MA: MIT Press.

[32] World Bank Group (2017). World Development Indicators 2017. Retrieved from https://openknowledge.org

Received: 2017-11-14

Revision requested: 2018-05-25

Revised: 2018-06-30

Accepted: 2018-07-03 


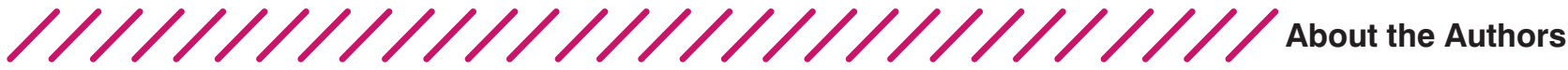

\section{Snežana Radukić \\ University of Niš, Faculty of Economics, Serbia snezana.radukic@eknfak.ni.ac}

Snežana Radukić is an Associate Professor at the Faculty of Economics, University of Nis. She teaches Price Theory and Policy and Microeconomics. She earned her Master's degree at the Faculty of Economics, University of Belgrade, in 2003, and a PhD at the Faculty of Economics, University of Niš in 2009. She has published a textbook, three monographs and dozens of scientific papers in journals and conference proceedings of international and national importance. She has been engaged in the projects of the Ministry of Education, Science and Technological Development of Republic of Serbia since 1999. The areas of her interest are: microeconomics, state intervention, environmental protection.

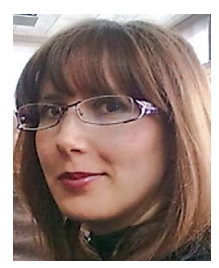

Dušan Perović

University of Niš, Faculty of Economics, Serbia dulep89@gmail.com

Dušan Perović is a PhD student at the Faculty of Economics, University of Niš. He obtained his Bachelor's and Master's degrees at the Faculty of Economics, University of Niš after which he enrolled in PhD studies at the same faculty. He participated at many domestic and foreign scientific conferences, seminars and workshops. He also published some of his scientific papers in many domestic journals and conferences. He lives in Niš. He speaks English, German and French. 